\title{
Are inhaled corticosteroids increasing the "load" for some patients with COPD?
}

\author{
Tom M.A. Wilkinson
}

Affiliation: Dept of Clinical and Experimental Sciences, University of Southampton Faculty of Medicine, Southampton General Hospital, Southampton, UK.

Correspondence: Tom M.A. Wilkinson, Dept of Clinical and Experimental Sciences, University of Southampton Faculty of Medicine, Southampton General Hospital, Southampton, UK. E-mail: T.wilkinsondsoton.ac.uk

@ERSpublications

Inhaled corticosteroids cause increases in sputum bacterial load in COPD patients with lower eosinophil levels http://ow.ly/kCcS30feTru

Cite this article as: Wilkinson TMA. Are inhaled corticosteroids increasing the "load" for some patients with COPD? Eur Respir J 2017; 50: 1701848 [https://doi.org/10.1183/13993003.01848-2017].

\begin{abstract}
The clinical burden of chronic obstructive pulmonary disease (COPD) remains one of the most significant unmet needs not only in respiratory medicine but in global health $[1,2]$. Despite drives to improve diagnosis rates, encourage smoking cessation and improve function with pulmonary rehabilitation and prescription of inhaled therapies, impacts on quality of life and healthcare resources continue to place an unacceptable load on both patients and health services [1]. A key driver for this health burden is acute exacerbations, which continue to affect a patient's health even after optimal medical management is in place [1].

One of the key complexities of treating COPD patients is the marked heterogeneity of disease from patient to patient and in their subsequent response to therapy [3]. This complexity is even greater when considering acute exacerbations. A number of studies have identified a key role for infection, both viral and bacterial $[4,5]$, in triggering exacerbations and modifying their severity [6]. However, despite their association with acute infections, exacerbations are far from random events and frequent exacerbation appears to be both a sustained and clinically important phenotype in many patients $[7,8]$. This persistent trait suggests the presence of a key intrinsic feature in some patients which contributes to exacerbation risk and highlights the need for additional treatment in that group. Understanding the nature of this factor, and therefore the drivers to exacerbation risk, has led to studies of airway inflammation. Here two key endotypes of disease start to emerge: those associated with a signature of eosinophils and with one of neutrophils $[9,10]$. There is a current interest and a growing body of data to suggest that measurement of biomarkers in either blood or sputum may help predict response to therapy [9].
\end{abstract}

It is in this context that we revisit the role of inhaled corticosteroids (ICS), an important and widely used treatment for patients with COPD [11]. Many studies have identified potential benefits of ICS prescription for patients in terms of lung function, symptom control and exacerbation prevention [12-14]. This has seen them established as a mainstay of guideline supported therapy [15]. However, recently a number of reports have highlighted potential deleterious effects of ICS in some patients, with increased risk of pneumonia identified in both interventional $[16,17]$ and observational studies [18]. The identification that ICS use in COPD may carry both benefit and risk has led a drive to find clinical tools to help stratify patients and predict response [19]. Post hoc analysis of ICS intervention trials has identified that eosinophilic inflammation is a marker of steroid response [9], with patients manifesting evidence of

Received: Sept 082017 | Accepted: Sept 142017

Conflict of interest: Disclosures can be found alongside this article at erj.ersjournals.com

Copyright @ERS 2017 
eosinophilic inflammation receiving the most benefit from treatment. This is perhaps of little surprise considering the key role of ICS in the management of asthma [20] and the understanding of eosinophilic inflammation as conventionally steroid responsive in this condition [21]. However, clinicians remain uncertain as to which COPD patients will and will not benefit from ICS use, and understanding of the mechanisms which define this heterogeneity of response is lacking.

The evolving field of respiratory molecular microbiology has identified that the airways are far from sterile, but are, in both health and disease, inhabited by rich microbial communities that influence lung health and immune vigour [22]. Recent studies have identified that COPD is associated with an abnormal microbial pattern compared with healthy lungs [23, 24]. This dysbiosis may be a key driver to both ongoing inflammation and risk of exacerbation [5]. The intrinsic status of the airway milieu is therefore intimately connected to the constant interaction between the microbiome and host mucosal immune and inflammatory responses and any disruption of this may have adverse effects.

The study by Contoli et al. [25], published in the European Respiratory Journal, is timely in its investigation of this phenomenon. By using a randomised controlled interventional study they sought to investigate the direct impact of ICS on sputum bacterial load over a 12-month period and importantly to stratify responses by patient eosinophils levels in both blood and sputum. The importance of using bacterial load as a key index of microbiological status has long been debated [26], but its choice is supported by previous observations that higher bacterial loads have been associated with greater levels of neutrophilic airway inflammation [10] and lung function decline [27].

Despite a relatively small sample size, with 30 patients in each of the treatment (ICS/long-acting $\beta 2$ agonists (LABA)) and control (LABA) arms, the study generates some significant and fascinating results. Both groups had comparable airway bacterial loads at baseline, but after 1 year of treatment the ICS group had manifest a significant rise in load not seen in the LABA arm. Furthermore, a trend towards greater numbers of potentially pathogenic bacteria, especially the key pathogen nontypeable Haemophilus influenzae, was seen in the ICS group. No effect on the incidence of viral infection was seen, although sample numbers were small and overall detection rates were low. Perhaps most interesting was the relationship between ICS effects on bacterial load and eosinophil levels prior to study intervention. The rise in bacterial load driven by ICS use was only seen in patients with low $(<2 \%)$ sputum or blood eosinophils measured prior to commencing the intervention.

The study is small, but follow-up over a year and the use of steroid naïve patients ameliorated some of the effects of small sample size on measured effects. There are a number of technical considerations regarding the methods used, which are acknowledged in the paper, including the type of microbial analysis performed: a biased $16 \mathrm{~S}$ rRNA PCR assay rather than the more definitive DNA sequencing approach. A full description of the exact nature of the microbial diversity leading to increasing loads is consequently incomplete. Furthermore, measurement of sputum cell counts failed to elicit differences in inflammatory profiles in follow-up, stable-state samples out to 1 year so the real importance of rising load in stable disease remains uncertain but at exacerbation higher loads were related to more neutrophilic inflammation.

Despite these issues, the finding that ICS use leads to greater levels of bacterial colonisation in non-eosinophilic COPD raises many important questions about the role of eosinophils and the mechanisms by which microbial dysbiosis develops in COPD. Eosinophils themselves can play an important role in the immune response to bacterial infection; both by secretion of antibacterial proteins [28] and by coordinating adaptive immune responses [29]. The relevance of this cell type is underwritten by a recent analysis for the AERIS COPD (Acute Exacerbation and Respiratory Infections in COPD) cohort that suggests eosinophil-associated inflammation appears to be a relatively stable clinical phenotype in COPD and one that persists despite the long-term use of ICS-containing inhaled treatment [30]. The concept that these patients with eosinophil-associated disease are somewhat protected from the deleterious effects of ICS use on bacterial infection resonates with the reanalyses of clinical trials demonstrating additional clinical benefit in this group [9].

The fine equipoise of airway immune responses balance microbial control with minimal inflammation and can be dramatically influenced by therapy. Modern inhaled steroids are potent immunomodulatory drugs and their impact in COPD, which is associated with pre-existing immune dysfunction, may be even more significant than in other conditions [31]. ICS have been shown to downregulate many key aspects of innate and adaptive immunity [32]; recently, we have shown that ICS use in COPD is associated with a significant drop in the numbers and function of a key arm of the immune response to the microbiome: the mucosal associated invariate T-cell (MAIT) [33]. The fact that ICS may impair these responses and that colonising bacteria may gain an advantage is therefore not surprising; however, the key mechanistic question arising from this study is why are patterns of eosinophilic inflammation not associated with 
adverse changes in microbial load and how is this patient group "protected" from the adverse effects of ICS and its impact on bacterial infection. More work is required to better understand this and to subsequently develop new and better approaches to treatment.

There is an emerging narrative that the "yin and yang" of airway endotypes in COPD are eosinophilic and neutrophilic dysbiotic inflammation. Ultimately these disease traits are more than simple markers of ICS response and detailed studies of the mechanisms of disease and therapeutic response are required to give us new and perhaps discrete approaches to effective disease modifying interventions. Considering the long standing and competing theories of COPD origins, in the era of Brexit, perhaps Anglo-European accord can be helped by accepting that both the British and the Dutch hypotheses appear to be valid [34]; describing parallel, but distinct biological origins of disease that require quite different approaches to treatment. If we are to define the new era of a more personalised approach to treating COPD, informative studies such as the one by Contoli et al. [25] are key to improving our understanding of disease and to the better design of definitive intervention trials that are needed to lighten the load for our patients.

\section{References}

1 Rabe KF, Hurd S, Anzueto A, et al. Global strategy for the diagnosis, management, and prevention of chronic obstructive pulmonary disease: GOLD executive summary. Am J Respir Crit Care Med 2007; 176: 532-555.

2 Buist AS, Vollmer WM, McBurnie MA. Worldwide burden of COPD in high- and low-income countries. Part I. The burden of obstructive lung disease (BOLD) initiative. Int J Tuberc Lung Dis 2008; 12: 703-708.

3 Agusti A, Sobradillo P, Celli B. Addressing the complexity of chronic obstructive pulmonary disease: from phenotypes and biomarkers to scale-free networks, systems biology, and P4 medicine. Am J Respir Crit Care Med 2011; 183: 1129-1137.

4 Wilkinson TMA, Hurst JR, Perera W, et al. Interaction of bacterial and rhinoviral infection during chronic obstructive pulmonary disease exacerbations. Chest 2006; 129: 317-324.

5 Wilkinson TMA, Aris E, Bourne S, et al. A prospective, observational cohort study of the seasonal dynamics of airway pathogens in the aetiology of exacerbations in COPD. Thorax. 2017; 72: 919-927.

6 Mallia P, Message SD, Gielen V, et al. Experimental rhinovirus infection as a human model of chronic obstructive pulmonary disease exacerbation. Am J Respir Crit Care Med 2011; 183: 734-742.

7 Seemungal TA, Donaldson GC, Paul EA, et al. Effect of exacerbation on quality of life in patients with chronic obstructive pulmonary disease. Am J Respir Crit Care Med 1998; 157: 1418-1422.

8 Hurst JR, Vestbo J, Anzueto A, et al. Susceptibility to exacerbation in chronic obstructive pulmonary disease. N Engl J Med 2010; 363: 1128-1138.

9 Bafadhel M, Davies L, Calverley PM, et al. Blood eosinophil guided prednisolone therapy for exacerbations of COPD: a further analysis. Eur Respir J 2014; 44: 789-791.

10 Hill AT, Campbell EJ, Hill SL, et al. Association between airway bacterial load and markers of airway inflammation in patients with stable chronic bronchitis. Am J Med 2000; 109: 288-295.

11 Ernst P, Saad N, Suissa S. Inhaled corticosteroids in COPD: the clinical evidence. Eur Respir J 2015; 45: 525-537.

12 Vestbo J, Sorensen T, Lange P, et al. Long-term effect of inhaled budesonide in mild and moderate chronic obstructive pulmonary disease: a randomised controlled trial. Lancet 1999; 353: 1819-1823.

13 Burge PS, Calverley PM, Jones PW, et al. Randomised, double blind, placebo controlled study of fluticasone propionate in patients with moderate to severe chronic obstructive pulmonary disease: the ISOLDE trial. BMJ 2000; 320: 1297-1303.

14 Calverley PM, Boonsawat W, Cseke Z, et al. Maintenance therapy with budesonide and formoterol in chronic obstructive pulmonary disease. Eur Respir J 2003; 22: 912-919.

15 National Institute for Health and Care Excellence. Chronic obstructive pulmonary disease in over 16s: diagnosis and management. Clinical guideline [CG101]. London, NICE, 2010. https://www.nice.org.uk/guidance/CG101

16 Crim C, Calverley PM, Anderson JA, et al. Pneumonia risk in COPD patients receiving inhaled corticosteroids alone or in combination: TORCH study results. Eur Respir J 2009; 34: 641-647.

17 Suissa S. Number needed to treat in COPD: exacerbations versus pneumonias. Thorax 2013; 68: 540-543.

18 Suissa S, Patenaude V, Lapi F, et al. Inhaled corticosteroids in COPD and the risk of serious pneumonia. Thorax 2013; 68: 1029-1036.

19 Agusti A, Bel E, Thomas M, et al. Treatable traits: toward precision medicine of chronic airway diseases. Eur Respir J 2016; 47: 410-419.

20 Reddy AP, Gupta MR. Management of asthma: the current US and European guidelines. Adv Exp Med Biol 2014; 795: 81-103.

21 Brightling CE, GreenIan RH, Pavord I. Biomarkers predicting response to corticosteroid therapy in asthma. Treat Respir Med 2005; 4: 309-316.

22 Cui L, Morris A, Huang L, et al. The microbiome and the lung. Ann Am Thorac Soc 2014; 11: Suppl 4, S227-S232.

23 Wang Z, Bafadhel M, Haldar K, et al. Lung microbiome dynamics in COPD exacerbations. Eur Respir J 2016; 47:1082-1092.

24 Sze MA, Hogg JC, Sin DD. Bacterial microbiome of lungs in COPD. Int J Chron Obstruct Pulmon Dis 2014; 9: 229-238.

25 Contoli M, Pauletti A, Rossi MR, et al. Long-term effects of inhaled corticosteroids on sputum bacterial and viral loads in COPD. Eur Respir J 2017; 50: 1700451.

26 Wilkinson TM. Host pathogen interactions during COPD exacerbations: moving on from microbiology by numbers? Am J Respir Crit Care Med 2007; 176: 323-325.

27 Wilkinson TMA, Patel IS, Wilks M, et al. Airway bacterial load and FEV1 decline in patients with chronic obstructive pulmonary disease. Am J Respir Crit Care Med 2003; 167: 1090-1095. 
28 Malik A, Batra JK. Antimicrobial activity of human eosinophil granule proteins: involvement in host defence against pathogens. Crit Rev Microbiol 2012; 38: 168-181.

29 Shi H-Z. Eosinophils function as antigen-presenting cells. J Leukoc Biol 2004; 76: 520-527.

30 Kim VL, Coombs NA, Staples KJ, et al. Impact and associations of eosinophilic inflammation in COPD: analysis of the AERIS cohort. Eur Respir J 2017; 50: 1700853.

31 McKendry RT, Spalluto CM, Burke H, et al. Dysregulation of antiviral function of $\mathrm{CD}^{+} \mathrm{T}$ Cells in the chronic obstructive pulmonary disease lung. Role of the PD-1-PD-L1 axis. Am J Respir Crit Care Med 2016; 193: 642-651.

32 Lee C, Klaustermeyer WB. Effect of high dose inhaled corticosteroids on cell mediated immunity in patients with asthma. Allergol Immunopathol (Madr) 2012; 40: 100-103.

33 Hinks TS, Wallington JC, Williams AP, et al. Steroid-induced deficiency of mucosal-associated invariant T cells in the chronic obstructive pulmonary disease lung. Implications for nontypeable Haemophilus influenzae infection. Am J Respir Crit Care Med 2016; 194: 1208-1218.

34 Ghebre MA, Bafadhel M, Desai D, et al. Biological clustering supports both "Dutch" and "British" hypotheses of asthma and chronic obstructive pulmonary disease. J Allergy Clin Immunol 2015; 135: 63-72. 